\title{
EMPLOYEE-OWNED FIRMS FROM A STAKEHOLDER PERSPECTIVE
}

\author{
JOSEFINA FERNÁNDEZ-GUADAÑO* [D and MANUEL LÓPEZ-MILLÁN \\ Department Accounting and Finance, Complutense University, Faculty of Economics Science, \\ Madrid, Spain
}

\begin{abstract}
This study focuses on the role of employee-owned firms (EOFs) in value creation from a stakeholder perspective. EOFs have been defined as Social Economy enterprises in Spain following guiding principles that in our opinion should empower stakeholder governance. Therefore, the impact of employee share ownership on value creation for shareholders and stakeholders has been measured on the basis of a sample of 1006 enterprises. The results reveal that EOFs have a positive and significant influence on the distribution of value in favour of the employees but not the other stakeholders. This finding, which allows us to partially accept one of the proposed hypotheses, is consistent with previous evidence that EOFs set their objectives to maximize the value obtained by the participating employees through their financial participation in the business, and not, therefore, to maximize profits. Copyright () 2018 John Wiley \& Sons, Ltd.
\end{abstract}

Keywords: employee-owned firms; non- employee-owned firms; stakeholder theory; shareholder theory; social economy; Spain

\section{INTRODUCTION}

The Employee share ownership movement, which can take on many different forms in different countries, is clearly young but growing in importance for researchers, policymakers and firms (Poutsma, Nijs, \& Poole, 2003; Kim \& Patel, 2017). Among other factors, the recent financial, economic and sovereign debt crisis has increased public interest in socially oriented business models as an alternative to the exaggerations of the shareholders' value and profit driven models (ICA, 2015).

When traditional economic organizations are unable to meet stakeholder expectations, other business models such as employee-owned firms (EOFs) could become an optimal solution as they are expected to address social and economic performance simultaneously

*Correspondence to: Josefina Fernández-Guadaño, Department Accounting and Finance, Complutense University, Faculty of Economics Science, Campus de Somosaguas, E-28223 Pozuelo de Alarcón, Madrid, Spain. E-mail: jofernan@ucm.es 
(Narvaiza, Aragon-Amonarriz, \& Iturrioz-Landart, 2016). We can therefore talk about a creative culture of value for all stakeholders, in which social enterprises operate and feel responsibility, which is a key factor in business survival during a recession (Hannan, 2014; Muñoz-Medrano \& Briones-Peñalver, 2011).

According to Wills (1998), proponents of a 'stakeholding' society have advocated broadening share ownership as a means of democratizing the economy, building partnerships and achieving consensus at work. We want to measure the impact of employee share ownership on value creation, but for both shareholders and stakeholders. The purpose of the research is to test whether EOFs are a business model that generates value for both partner-employees and all other stakeholders.

The typical form of employee financial participation in Spain is 'workers' companies' (EOFs), which combine employee share ownership with decision-making rights; the model can be considered successful if we take into account the figures in terms of the number of affected employees and businesses (Lowitzsch, Hashi, \& Woodward, 2009). According to Fajardo-García, Muñecas, and San José (2016), it is a business model that promotes worker participation at the highest level by bringing together participation in ownership with participation in management and control; it is a model that generates wealth and quality employment wherever the activity is carried out; and it has shown itself to be a business model that is valid both in times of crisis, guaranteeing employment and the continuance of the company, and in times of economic growth, as a collective learning model.

The workers' company has one special feature in that it enjoys a specific alternative legal status (Law 44/2015 modify the previous Law 4/1997) of employee share ownership. This new Law on Worker-Owned and Participatory Companies in Spain could be a model for further policy action (Lowitzsch, Dunsch, \& Hashi, 2017), making it different from cooperative companies, and it is a model found in the Social Economy (Law 5/2011). According to Blasi and Kruse (1991) the term 'employee-owned' is reserved for corporations or legal entities where employees own more than 51 per cent, meaning that most of their employees are broadly represented. The regulation of this Spanish model makes it possible to compare it with the conventional capitalist firm.

These enterprises can play an important role in job creation. They are based on employee ownership whose demonstrated benefits complement the policy aims of Active Labour Market Policies (Lowitzsch et al., 2017). The aim of this research is to determine whether the social enterprise model represented by the EOF in Spain positively influences value creation for shareholders and stakeholders, offering an alternative approach to the conventional active labour policies.

In fact, the development of this employee-based corporate governance model in Spain, found in the Social Economy and characterized by employee self-management, generates significant gains in terms of welfare (Fernández-Guadaño, 2015). The Social Economy can contribute a new dynamism to Stakeholder Theory (Retolaza \& San, 2011). The Social Economy is characterized by a distinctive culture with a strong social orientation designed to meet the needs of various stakeholders, especially employees and customers (MuñozMedrano \& Briones-Peñalver, 2011). According to Wills (1998), fixing capital in place through ownership relationships is an obvious route to sustaining long-term investment in local production, reproduction and community life, but we know little about its success. In this paper, we want to test whether welfare is shared between all the stakeholders because in the study of corporate governance there is a bias towards shareholder interest, in detriment to stakeholder interest. A more recent view has gradually emerged that deals 
with stakeholder governance, especially the employees, creditors, customers, state and other suppliers (Bendixen \& Russel, 2007; Poulain-Rehm \& Lepers, 2013).

As a result, this paper analyses whether the EOF model generates value for both shareholders and stakeholders. Two hypotheses will therefore be tested in relation to each of these two groups, and the results found for EOFs and non-EOFs will be compared in order to analyse whether their different capital-ownership structures can be a factor in value creation.

For this purpose, this research has been structured as follows: firstly there is a description of Employee Owned Firms, their legal status in Spain and their recent inclusion in the Social Economy by law; this is followed by the relevant theoretical work in this area; thirdly, the methodology and statistical models are presented; in the penultimate section, the empirical results of formulating and testing the hypotheses are shown; the final section outlines the conclusions.

\subsection{EOFs versus Non-EOFs}

In Spain, employee-owned companies are a business model included in the Social Economy that must be capable of consolidating their position as an alternative to conventional capitalist companies, demonstrating their viability whilst also safeguarding their added social value (Chaves \& Monzón, 2012; Ciruela-Lorenzo, Cuadrado Serrán, \& Plaza Angulo, 2016). In addition to their managers playing the dual role of partners and employees, EOFs are characterized by being based on a set of values that go beyond the purely financial, also taking into account social aspects, and this contributes to the creation of high quality, stable jobs.

The results of EOFs for employees, productivity and all of the shareholders have been extensively studied by measuring financial profitability, with inconclusive results. However, the influence of employee share ownership on stakeholders has received less attention in the scientific literature. According to Poulain-Rem and Lepers (Poulain-Rehm \& Lepers, 2013), the analysis paradigm of value creation is evolving, leading to the consideration of employee share ownership from a stakeholder governance perspective.

According to the specific legislation (Law 44/2015), what makes a company an EOF is that the employees with full time, open-ended contracts with the firm must own at least 51 per cent of its capital. With a minimum of three partners required to set up such a company, ${ }^{1}$ the distribution of capital per partner is also regulated in such a way that no partner can individually own more than one third of the company. In these firms, it is the employee-partners who control the company because they own the majority of the share capital. In recognition of their social and economic purpose, EOFs have fiscal advantages such as tax breaks and exemptions, but none in terms of tax benefits.

In contrast, non-EOFs are firms in which partner status is achieved through the capital provided and thus is a means and an end in itself. Financial partnership in this type of company does not imply participation in other business processes. The Spanish legal framework allows for different types of non-EOF, such as the Public Limited Company and Limited Liability Company. For the purposes of a more homogeneous study, the focus here is on the second. The smaller sum of capital involved, the lower start-up costs, the

\footnotetext{
${ }^{1}$ There are also exceptions to these requirements such as the chance to set up employee-owned firms with two partners, as long as both are employees and they hold equal shares in the company.
} 
unlimited number of partners and the ability to simultaneously be a personalized yet capital company are among the features of a limited liability company that make it the most common legal structure for business organization in Spain if we consider the number of enterprises in the latest official figures (Fernández-Guadaño, 2014).

\subsection{Theoretical Background}

Stakeholder governance has been defined as the amalgam of good corporate governance (protecting shareholders' interests), sound stakeholder relations (protecting the interests of other stakeholders, including employees and local communities) and environmental care (protecting the environment) (Freeman, 1984; Renneboog, Ter Horst, \& Zhang, 2008). EOFs have been defined as social economy enterprises in Spain, and according to Law 5/2011 on the Social Economy (Article 4), this type of company is characterized by the following principles:

a Primacy of people and social aspects over capital, as embodied in management that is autonomous and transparent, democratic and participatory.

b Distribution of the results of the economic activity primarily on the basis of the work contributed or the service or activity performed by the partners.

c Promotion of solidarity, internally and in society as a whole, which encourages a commitment to local development and the generation of high quality, stable employment.

d Independence from the political powers.

These principles of the Social Economy empower stakeholder governance. EOFs are characterized by being based on a set of values that go beyond the purely financial, also taking into account social aspects, and this contributes to better governance. In fact, according to Retolaza and San (2011), the integration of the Social Economy paradigm with stakeholder theory generates a reciprocal benefit. Following Fassin, Colle, and Edwart Freeman (2016), we take stakeholder theory to be a managerial approach enabling organizations to create as much value as possible for stakeholders, including shareholders. EOFs, as social economy enterprises, should be better placed to generate value for all the stakeholders because this is inherent in the guiding principles of the Social Economy. Their social orientation and inclusive governance have a positive impact on strengthening social cohesion and achieving sustainable economic growth based on the local development of the regions and the well-being of communities (Chaves \& Monzón, 2012).

It is also widely recognized in the literature that the search for financial objectives, defined in the terms of a capitalist company (shareholder theory), cannot be directly extrapolated to the objectives of associated work companies (Lejarriaga, 2002). Since most partners are not just shareholders, they have multiple residual rights to income (Fama \& Jensen, 1983). The uniqueness of the connections that partners of the EOF may have in their role as working partners makes it necessary to look at alternative economic efficiency parameters in order to carry out a homogeneous comparative analysis that deals with the different approaches to the business model (Zubiaurre, Andicoechea, \& Saitua, 2016).

The partner-employees in EOFs who participate in the real, financial and informationaldecisional aspects may choose to reduce profits, or even do away with these altogether, anticipating them through labour income, thus affecting the objective function, and, therefore, the return on the capital they provide. In this sense, decisions will only be taken 
to capitalize the profits obtained to the extent that this serves to ensure the maintenance of the productive capacity of the company (Fernández-Guadaño, 2014).

According to Cahill (2000), implementing plans to encourage financial participation in firms allows the risks and profits to be shared, leading to advantages for both the companies themselves and the employees. Following Maghraoui and Zidai (2016), many theoretical and empirical studies have shown that the most successful companies in terms of productivity are those that have adopted a degree of employee ownership, whatever its form (Freeman, Joseph, \& Douglas, 2011; Kruse, Freeman, \& Blasi, 2010). The underlying reasoning is that the firm is seen from the perspective of a stakeholder, is developing a cooperative culture that enhances the many existing interactions between employees and is fostering collaboration between them and effective mutual control, which are all factors that affect productivity and contribute to its improvement (Blasi et al. 2008). However, according to Dow (2001), in the short-term EOFs assume inefficient behavior that limits their options for growth, production and employment, by establishing an average income per partner-worker unrelated to that offered in the labour market, and this influences worker productivity and firm competitiveness.

There are several studies that analyse the impact of employee share ownership on economic performance, focusing primarily on measures of value for the shareholders, but the results are inconclusive (Kim \& Patel, 2017, O’Boyle, Patel, \& González, 2016). The mixed evidence in the literature might be due to the diversity of forms of employeeownership. Systematic differences in cultural and institutional conditions across countries, variations in labour market regulations, tax systems and company laws (Kim \& Patel, 2017) could explain variations in the influence of employee ownership on performance (Caramelli \& Briole, 2007).

In short, we can find controversial results related to these differences, but we agree with Poulain-Rehm and Lepers (2013) who argue that while the examination of the influence of employee share ownership on shareholder value creation remains incomplete and with contradictions, the analysis of the impact on stakeholder value creation is still an untouched field for research. For this reason, we want to analyse whether employee share ownership, represented by EOFs, may represent a factor in value creation for shareholders and stakeholders. To achieve this objective, we test the following two hypotheses:

Hypothesis 1. EOFs positively influence shareholder value creation.

Hypothesis 2. EOFs positively influence stakeholder value creation.

\section{RESEARCH METHOD}

\subsection{Data Collection}

The field study carried out is a statistical analysis of the two types of companies, EOFs and non-EOFs, having selected a sample of each from active Spanish enterprises with all the necessary economic-financial data ${ }^{2}$ in the Orbis from 2011 to 2014. Moreover, companies

\footnotetext{
${ }^{2}$ As $99 \%$ of EOFs are small and medium size companies, the non-EOFs have been filtered taking this criteria into account to homogenize the companies compared.
} 
with negative value added for one of the years during this period were removed. ${ }^{3} \mathrm{~A}$ number of other companies were eliminated due to missing data. We also omitted firms in the primary sector (agriculture, foresting and fishing) due to the small number of observations in this activity, and from the service sector we also excluded banks, lending institutions, finance companies, holding companies and real-estate companies given their specific financial characteristics. Once the sample had been filtered, it was found that there were no medium EOFs (50-229 workers), so non-EOFs of that size were also removed to make the comparison as homogeneous as possible. Therefore, the final sample includes 1006 firms split into $n=440$ non-EOFs and $n=566$ EOFs.

The firms analysed are operating in the higher economic sectors, i.e. secondary and tertiary (see Table 1), in accordance with the National Classification of Economic Activities (2009), with data grouped into two sectors: secondary (including industry + construction) and tertiary (including commerce + services) (following the criteria used for the Ministry of Industry's Companies Central Directory).

The second criterion for classifying the firms is size, taking as our reference the classification proposed by the European Union based on the number of employees. ${ }^{4}$ It is notable that all of the firms in our sample (see Table 2), taking into consideration the latest number of employees, are in the micro and small categories.

Finally, the firms in the sample have been classified on the basis of age, and we can see in both samples that the majority of the firms were founded in 1990 or later (see Table 3). However, the EOFs are younger because the majority of these were founded in 2000 or later, probably motivated by government efforts to create employee-participation firms and encouraging their creation through subsidies and measures such as the total capitalization of unemployment benefits.

\subsection{Selection of Economic Variables}

\subsubsection{The dependent variables}

Following Poulain-Rehm and Lepers (2013), value added ${ }^{5}$ distribution in the accounting sense was adopted as a dependent variable because the distribution of value added in favour of other stakeholders, such as employees, creditors, the state and shareholders, can be measured using financial documents:

- For employees, we measure the proportion of value added absorbed by personnel costs.

- For creditors, we measure the proportion of value added devoted to paying interest and similar charges.

\footnotetext{
${ }^{3}$ If we wish to observe how the value added is distributed among the different stakeholders, it does not make sense for this to be negative.

${ }^{4}$ Recommendation 2003/361/EC of the Commission, dated 6 May 2003, concerning the definition of micro, small and medium-sized enterprises [Official Journal L 124 of 20.5.2003], provides that on the basis of the number of employees, micro-enterprises will be those with fewer than 10 employees, small enterprises will be those that have between 10 and 49 employees, medium-sized enterprises those that have between 50 and 249 employees, and large enterprises those that have 250 or more employees.

${ }^{5}$ The Value Added variable is an indicator of the operational or economic activity of the firm that does not consider personnel costs which, in the case of EOFs, can skew the results due to their dual partner-employee status. The VA is considered to be stakeholder value (Maghraoui \& Zidai, 2016) because it is distributed to the employees, State, creditors, shareholders and used for the self- financing of the entity.Value Added is the difference between the total sales revenue and the total costs incurred to obtain that revenue, without including depreciation, interest, taxes and salary costs. It is also possible to calculate this as:Value Added = Financial year result + Corporation Tax + Personnel Expenses + Depreciation Charges + Financial Expenses and similar.
} 
Table 1. Distribution of sample firms by sector of activity

\begin{tabular}{lrrrrr}
\hline Sector & \multicolumn{2}{c}{ Non-EOF } & & \multicolumn{2}{c}{ EOF } \\
\cline { 1 - 2 } & $N$ & Per cent & & $N$ & Per cent \\
\hline Secondary & 121 & 27.5 & & 264 & 46.6 \\
Tertiary & 319 & 72.5 & & 302 & 53.4 \\
Total & 440 & & 566 & \\
\hline
\end{tabular}

Source: author-compiled data.

Table 2. Distribution of sample firms by size

\begin{tabular}{lrrrrr}
\hline & \multicolumn{2}{c}{ Non-EOF } & & \multicolumn{2}{c}{ EOF } \\
\cline { 2 - 3 } \cline { 5 - 6 } & $N$ & Per cent & & $N$ & Per cent \\
\hline Micro (0-9 employees) & 342 & 78.11 & & 511 & 90.3 \\
Small (10-49 employees) & 98 & 21.9 & & 55 & 9.7 \\
Total & 440 & & 566 & \\
\hline
\end{tabular}

Source: author-compiled data.

Table 3. Distribution of sample firms according to their age

\begin{tabular}{lrrrrr}
\hline & \multicolumn{2}{c}{ Non-EOF } & & \multicolumn{2}{c}{ EOF } \\
\cline { 2 - 3 } \cline { 5 - 6 } & $N$ & Per cent & & $N$ & Per cent \\
\hline Before 1990 & 23 & 5.2 & & 0.7 \\
1990-2000 & 212 & 48.2 & & 168 & 29.7 \\
After 2000 & 205 & 46.6 & & 394 & 69.6 \\
Total & 440 & & 566 & \\
\hline
\end{tabular}

Source: author-compiled data.

- For the state, we measure the proportion of value added absorbed by profit tax.

- For shareholders, we estimate the proportion of value added paid as dividends. ${ }^{6}$

Distinguishing between alternative performance measures is important as these measures represent the performance expectations of different stakeholder groups. As the data series are stationary on average, we have calculated the average values of the variables for 2011-2014. Given that the distributions of these variables depart from normality, logarithmic transformations were used.

\subsubsection{Explanatory variables}

Different categories of explanatory variables were included. The independent dichotomous variable is employee share ownership, which takes the value: 0 if it is non-EOF and 1 if it is EOF. Financial and economic variables: financial risk and investment policy, both also

\footnotetext{
${ }^{6}$ The annual accounts do not provide information on the exact distribution of the profit decided by the partners, so we cannot know what amount reverts to the partners and what part remains in the company each year. However, as the accounts are submitted simultaneously for two consecutive years we can estimate the distribution from the changes in the reserves.
} 
measured in logarithmic form (2011-2014 average). Control variables: size and age are both measured in logarithmic form. Furthermore, we include a dummy variable for the sector of economic activity (see Table 4). All variables have been added on the basis that previous research has found them to be relevant (Melgarejo, Arcelus, \& Simon, 2014; Poulain-Rehm \& Lepers, 2013; Richter \& Schrader, 2017).

Table 5 summarizes the main descriptive statistics for the numeric variables used in the models to be assessed. As can be seen, non-EOFs have been operating for longer on average than EOFs and they have a larger number of employees; INV is also higher for non-EOFs than for EOFs while the DEBT coefficient is higher for EOFs than for nonEOFs. On the other hand, EMPL is higher on average for EOFs than for non-EOFs but STATE, CRED and SHARE are higher on average for non-EOFs than for EOFs.

Table 6 shows the bivariate correlations between the numeric variables in the models proposed. Here, we can see that there is a significant positive correlation between the variable EMPL with Size and DEBT and a negative one with INV. The variable STATE is negatively correlated with Size and DEBT. The variable CRED is significantly negatively correlated with the variable Size and positively with DEBT and INV. SHARE is negatively correlated with Size and DEBT. Pearson's correlation coefficients between explanatory variables were tested to determine the absence of multi-collinearity problems. ${ }^{7}$

An exploratory analysis has been developed to test the average differences between EOFs and non-EOFs. To study whether there are differences between the groups, we have applied non-parametrical tests (U-Mann and Kruskal-Wallis) to compare the value added distribution between EOFs and non-EOFs conducted in the presence of independent samples. The results (Table 7) reveal that there are significant differences in the distribution of value added for shareholders (SHARE) and stakeholders, EMPL and STATE, except for the creditors (CRED), a variable for which no significant differences between EOFs and non-EOFs were detected.

\subsection{Methodology}

To discern the impact of employee share ownership on shareholder and stakeholder value creation, we conduct an explanatory study in which we analyse four dependent variables (VA): SHARE (Model 1), EMPL (Model 2), STATE (Model 3) and CRED (model 4). Based on the hypotheses formulated and the related explanatory and control variables, the models used are as follows: VA $=\beta_{0}+\beta_{1}$ Prop $+\beta_{2}$ Size $\beta_{3}$ Age $+\beta_{4}$ Sector $+\beta_{5}$ Inv $+\beta_{6}$ Debt + e. The regression analyses are based on robust standard errors.

\section{RESULTS AND DISCUSSION}

To test the two main hypotheses, we established four models whose regression results are shown in Table 8. Specifically, Model 1 is proposed to test $\mathrm{H} 1$ and Models 2, 3 and 4 are proposed to test $\mathrm{H} 2$. Based on the results, it can be observed that $\mathrm{H} 1$ is rejected and $\mathrm{H} 2$ is rejected, except for the group of employees (model 2). This result is consistent

\footnotetext{
${ }^{7}$ According to Tabachnick and Fidell (1996), multi-collinearity shall only be considered a serious problem if the correlation coefficient between explanatory variables is higher than 0.8
} 
Table 4. Summary presentation of the variables of the study

\begin{tabular}{ll}
\hline Abbreviation of variable & \multicolumn{1}{c}{ Variables } \\
\hline Shareholder and stakeholder value creation & \\
EMPL & Log Personnel Cost/Value Added (2011-2014 average) \\
STATE & Log Profit Tax/Value Added (2011-2014 average) \\
CRED & Log Interest Expenses/Value Added (2011-2014 average) \\
SHARE & Log Dividends/Value Added (2011-2014 average) \\
Explanatory and control variables & \\
PROP & Type of firm, dichotomous variable: \\
& EOF = 1 \\
Size & Non-EOF $=0$ \\
Sector & Log latest number of employees \\
& Sector of economic activity \\
Age & Secondary $=0$ \\
Inv & Tertiary $=1$ \\
Debt & Log number of years in operation \\
\hline
\end{tabular}

Source: author elaboration.

Table 5. Descriptive statistics for the sample

\begin{tabular}{|c|c|c|c|c|c|c|}
\hline & \multicolumn{3}{|c|}{ Non-EOF } & \multicolumn{3}{|c|}{$\mathrm{EOF}$} \\
\hline & $N$ & Mean & Std. dev & $N$ & Mean & Std. dev \\
\hline Age & 440 & 13.93 & 5.670 & 566 & 10.86 & 3.370 \\
\hline Size & 440 & 7.04 & 7.52 & 566 & 4.95 & 4.695 \\
\hline INV & 440 & 1.13 & 5.064 & 566 & .647 & .913 \\
\hline DEBT & 440 & 74.73 & 28.50 & 566 & 78.27 & 28.59 \\
\hline EMPL & 440 & .817 & .235 & 566 & 0.888 & .259 \\
\hline STATE & 440 & .020 & .0266 & 566 & .0129 & .017 \\
\hline CRED & 440 & .054 & 0.788 & 566 & .0521 & .075 \\
\hline SHARE & 440 & .072 & .084 & 566 & .048 & .057 \\
\hline
\end{tabular}

Source: author-compiled data.

Table 6. Correlations

\begin{tabular}{|c|c|c|c|c|c|c|c|c|}
\hline & 1 & 2 & 3 & 4 & 5 & 6 & 7 & 8 \\
\hline 1 Age & 1 & & & & & & & \\
\hline 2 Size & $.185^{* * *}$ & 1 & & & & & & \\
\hline 3 INV & -.012 & $-.070^{*}$ & 1 & & & & & \\
\hline 4 DEBT & $-.141^{* *}$ & $-.086^{* *}$ & -.045 & 1 & & & & \\
\hline 5 EMPL & -.052 & $.106^{* *}$ & $-.236 * *$ & $.224 * *$ & 1 & & & \\
\hline 6 STATE & .013 & $-.102 * *$ & -.032 & $-.314 * *$ & $-.444 * *$ & 1 & & \\
\hline 7 CRED & -.055 & $-.179 * *$ & $.408 * *$ & $.194 * *$ & $-.201 * *$ & -.038 & 1 & \\
\hline 8 SHARE & .013 & $-.104 * *$ & .018 & $-.280 * *$ & $-.441 * *$ & $.802 * *$ & -.005 & 1 \\
\hline
\end{tabular}

Significance levels:

$* * p<.01$

$* p<.05$

Source: author-compiled data. 
Table 7. Average differences in tests ${ }^{1}$

\begin{tabular}{lrrrr}
\hline & \multicolumn{1}{c}{ EMPL } & \multicolumn{1}{c}{ STATE } & CRED & SHARE \\
\hline U Mann-Whitney & 104588.000 & 74899.500 & 122362.000 & 94584.000 \\
Wilcoxon W & 201608.000 & 183244.500 & 218065.000 & 237964.000 \\
Z & -4.318 & -3.752 & -.048 & -4.255 \\
Asymptotic sig. (bilateral) & .000 & .000 & .962 & .000 \\
\hline
\end{tabular}

Source: author-compiled data.

${ }^{1}$ Grouping variable PROP.

with the majority of the empirical evidence to date (Fernández-Guadaño, 2015; Melgarejo et al., 2014).

The examination of the different coefficients shows that the variable PROP appears significant in models 1, 2 and 3. Hence, our comments will only focus on the first three models. The results show that EOFs do not contribute to shareholder value creation (H1), and with regard to the influence of the EOFs on stakeholder value creation, a negative influence is observed in the STATE variable and a positive influence in the EMPL variable. This result is consistent with the findings from previous studies regarding employees (Fernández-Guadaño, 2014; Melgarejo et al., 2014). As in the findings from the study by Poulain-Rehm and Lepers (2013), it cannot be concluded that EOFs have a positive impact on the other stakeholders.

Likewise, the size variable has a negative influence in models 1 and 3, but this is not the case in model 2. The impact of investment (INV) policy appears to be negative on employees in the model. This result must be related to the fact that in the short term greater investment implies a reduction in the distribution of value to the employees, although investment is subsequently a value creation factor in the long term. As one might expect, there is a negative and significant influence for the debt variable on shareholder and state value creation, whereas this positively influences employees' interests in terms of value.

Consequently, based on the results, we can conclude that $\mathrm{H} 1$ is not verified and $\mathrm{H} 2$ is partially verified only for employees. We agree with Poulain and Lepers (2013), based on the results, that while employee share ownership is perceived as a way to develop stakeholder governance, we acknowledge that this does not in fact translate into a change in the value-added distribution in favour of all stakeholders.

Following Fajardo-García et al. (2016), in a report for the European Commission, experience has shown that a company controlled by its workforce, such as a workers' company, is managed differently as it aims to maintain employment and improved working conditions. The dual role of most of the shareholder-workers can help to avoid opportunistic behavior by the managers (Smith, 1991). The presence of shareholderworkers on the board helps to reduce the power differential between the managers and the other stakeholders, thus favouring the emergence of a co-operative coalition (Poulain-Rehm \& Lepers, 2013).

Recently, Kim and Patel (2017) classified employee ownership into four groups based on the percentage of employee stake: significant ownership (1\%-6\%), strategic ownership (6\%-20\%), determining ownership (20\%-50\%) and controlling ownership (50\%-100\%). In accordance with their proposal, EOFs in Spain would be considered "controlling ownership' to the extent that the employees must have, according to the legislation (Law $44 / 2015$, article 1.2), the majority of the share capital (more than 50\%). This legislation also establishes some practices that restrict the transferability of the shares (articles 6 to 


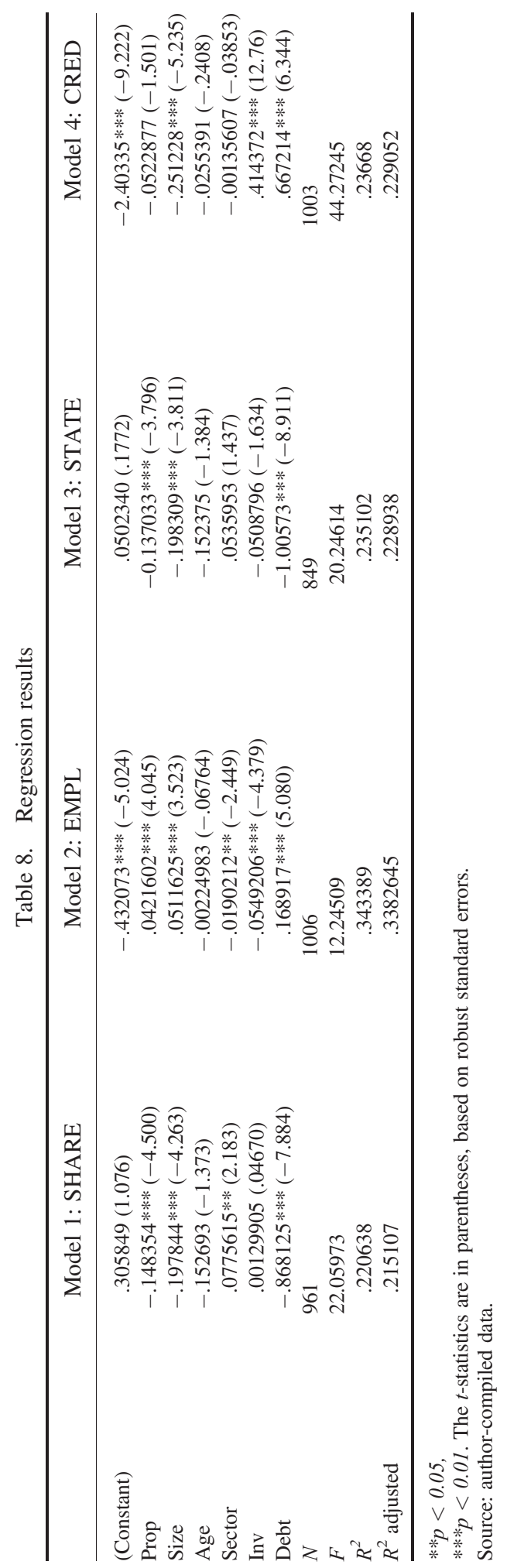


12), encouraging their sale to the non-partner employees of the company rather than to third parties, the objective being to enable employees to be shareholders. This confirms the findings of Kim and Patel (2017), who recognize that the effectiveness of employee ownership hinges upon various factors: both the country as well as firm-related factors (firm culture and human resources practices), among others, are shown to be very important. It also confirms the findings of Richter and Schrader (2017), who recognize that the dual findings regarding Spanish listed firms, with low ESO levels and weak performance effects in the few companies that have ESO, should be interpreted against the background of Spain's institutional framework. Spain has traditionally favoured another form of worker financial participation, namely through 'Workers' Companies' in which employees hold the majority of the shares.

In sum, the results from this study contribute to confirming what we have previously seen with regard to the employees, but they cannot be extended to the other stakeholders. The results, with regard to employees (Model 2), are consistent with the dominant theory which is the traditional idea that the objective of EOFs is to maximize rent per employee while for non-EOFs it is to maximize profit (Domar, 1966; Ward, 1958) and with the empirical evidence previously found for EOFs in Spain (Fernández-Guadaño, 2015). One must also take into account that the EOFs set their objectives to maximize the value obtained by the participating employees as a result of their financial participation in the business, and not, therefore, in terms of maximizing profits; in addition, the accounting results for employee-owned companies must be treated with a great deal of care because the peculiarities of the accounting for the results of these companies mean that they can anticipate the distribution of profits in the form of greater remuneration (Lejarriaga, 2002).

Employee Share Ownership has been accorded a key role in the process of leveraging improved performance via human resource management (Whitfield, Pendleton, Sengupta, \& Huxley, 2017). Employees with shares in the firm may strongly identify with the organization, which leads them to work hard on its behalf (Kim, Han, \& Baik, 2017). In this paper, the results provide evidence that can support 'the golden handcuffs perspective' (Sengupta, Whitfield, \& McNabb, 2007). This approach suggests that share ownership schemes function primarily as a worker retention tool and reduce labour turnover by making it financially lucrative for workers to remain in the firm (Morris, Bakan, \& Wood, 2006; Sengupta et al., 2007; Whitfield et al., 2017). Our results confirm that the main beneficiaries of the value-added distribution of EOFs are the workers, and this is what results in it being considered a benchmark business model by the European Union, which has recently recognized that Spanish EOFs provide an example of best practice in a Worker Financial Participation system for micro companies.

\section{CONCLUSIONS}

In this paper, our aim has been to demonstrate that stakeholder theory is a perspective that can be combined with the Social Economy, in accordance with its guiding principles. To do this, one of the business models in Spain that integrates the Social Economy has been chosen, EOFs, characterized by a majority holding by the employees of the three types of flows that occur in any business. This is based on the premise that EOFs, as social economy enterprises, should be better placed to generate value for all stakeholders, because this is inherent in their guiding principles. 
In this sense, while EOFs could be combined with stakeholder theory, in this paper, we have found that EOFs only have a positive influence on value-added distribution in favour of employees, not in favour of shareholders via dividends or the rest of the stakeholders. To demonstrate this, two hypotheses have been tested which have analysed whether employee share ownership, in the form of EOFs, could represent a value creation factor favouring shareholders and stakeholders. Four models have been proposed, one for the Shareholders (model 1) and the rest for three groups of stakeholders: employees (model 2); state (model 3) and creditors (model 4). The difference in the capital ownership structure between the two types of firm (variable PROP) is significant in the first three models, with a positive influence only on the value distribution for employees (EMPL) but not on that for shareholders (SHARE) or the state (TAXES). The four models demonstrate that EOFs tend to maximize the net income per employee, instead of total profits as their capitalist counterparts do, with the employees taking advantage of their dual status as shareholder and stakeholder. This result reveals, in line with previous studies (Lejarriaga, 2002), that EOFs set their objectives to maximize the value obtained by the participating employees as a result of their financial participation in the business, and not, therefore, in terms of maximizing profits.

We agree with Poulain-Rehm and Lepers (2013) who argue that participation in the firm's share capital and in the rest of the flows (productive and decision-making and representation bodies) creates an enterprise model where the partners-workers are allowed to influence the value-added distribution in terms of wages and participative remunerations. ESO schemes in Spanish EOFs benefit the workers more than the rest of the stakeholders, as suggested by the 'golden handcuffs' perspective, according to Lowitzsch et al. (2017), offering an alternative approach to the traditional Active Labour Market Policies that could play an important role across the EU as a proven model in use for more than three decades.

However, caution is still required in the interpretation of these results. Since EOFs in Spain are a legal structure that has no equivalent in any other European country, the results cannot be extrapolated. This study represents an innovative approach to operationalize stakeholder value creation but is not free from limitations that should be addressed in future research. First, our sample only includes micro and small enterprises, and the results could be different for large and medium-sized companies. Future research should explore the effects of ESO in such firms. Second, while a dichotomous variable has been used in the employee ownership literature, its usage as a main predictor is still a limitation. To improve the precision of the results, it would be possible to define ESO as a continuous variable, with different levels on the basis of the percentage of capital held by the employees. This would require a different methodology, such as spline regression. This technique allows the estimation of the relationship between the independent variable of interest and the dependent variable as a piecewise linear function (Greene, 2008). Future research should explore this issue because the results may change depending upon the different percentages of capital held by employees.

\section{ABBREVIATIONS}

EOF employee-owned firms

Non-EOF non-employee-owned firms 


\section{REFERENCES}

Bendixen M, Russel A. 2007. Corporate Identity, Ethics and Reputation in Supplier-Buyer Relationships. Journal of Business Ethics 76(1): 69-82.

Blasi J, Kruse D. 1991. The New Owners. Harpper Collins: New York.

Blasi J, Richard F, Mackin C, Douglas K. 2008. Creating a Bigger Pie? The Effects of Employee Ownership, Profit Sharing, and Stock Options on Workplace Performance, Presented at NBER/Russell Sage Foundation Conference, New York.

Cahill N. 2000. Profit Sharing, Employee Share Ownership and Gainsharing: What can they Achieve? NESC (National Economic and Social Council). Research Series.

Caramelli M, Briole A. 2007. Employee Stock Ownership and Job Attitudes: Does Culture Matter? Human Resource Management Review 17: 290-304.

Chaves R, Monzón JL. 2012. Beyond the Crisis: The Social Economy, Prop of a New Model of Sustainable Economic Development. Service Business. International Journal 6: 5-26.

Ciruela-Lorenzo AM, Cuadrado Serrán M, Plaza Angulo JJ. 2016. The Social Economy as an Alternative of Self Employment. Revesco. Journal of Cooperative Studies 122: 59-85.

Domar ED. 1966. The Soviet Collective Farm as a Producer Cooperative. American Economic Review 56(4): 734-757.

Dow G. 2001. Allocating Control Over Firms: Stock Markets Versus Membership Markets. Review of Industrial Organization 18: 201-218.

Fajardo-García G, Muñecas J, San José J. 2016. Employee Financial Participation: Spain's Sociedades Laborales. European Parliament: DIRECTORATE GENERAL FOR INTERNAL POLICIES. IP/AEMPL/2016-01.

Fama E, Jensen M. 1983. Agency Problems and Residual Claims. The Journal of Law and Economics 26(2): 301-325.

Fassin Y, Colle S, Edwart Freeman R. 2016. Intra-Stakeholder Alliances in Plant-Closing Decisions: A Stakeholder Theory Approach. Business Ethics: A European Review 26: 97-111. https://doi. org/10.1111/beer.12136

Fernández-Guadaño J. 2014. Employee-Owned and Capitalist Firms: Is Performance Linked to Ownership? Service Business. An International Journal 8(4): 541-558. https://oi.org/10.1007/ s11628-013-0206-x.

Fernández-Guadaño J. 2015. Employee-Owned Firms: A Business Model of Social Economy with Potential. Transformations in Business and Economics 14(2): 191-203.

Freeman RB, Joseph RB, Douglas LK. 2011. Inclusive Capitalism for the American Workforce: Reaping the Rewards of Economic Growth Through Broad-based Employee Ownership and Profit Sharing, Center for American Progress, Washington D.C.

Freeman RE. 1984. Strategic Management: A Stakeholder Approach. Pitman-Ballinger: Boston.

Greene WH. 2008. Econometric Analysis. Prentice-Hall: Upper Saddle River, NJ.

Hannan R. 2014. Good Co-Operative Governance: The Elephant in the Room with Rural Poverty Reduction. Journal of International Development 26: 701-712. https://doi.org/ 10.1002/jid.2989

International Cooperative Alliance-ICA 2015. Co-operative Governance Fit to Build Resilience in the Face of Complexity. Avaible at: http://ica.coop/en/co-operative-governance-fit-build-resilienceface-complexity.

Kim KY, Han JH, Baik K. 2017. Identification with the Organization: The Contribution to Organizational Financial Performance. Academy of Management Proceedings 2017(1): 14974.

Kim KY, Patel PC. 2017. Employee Ownership and Firm Performance: A Variance Decomposition Analysis of European Firms. Journal of Business Research 70: 248-254. 
Kruse DL, Freeman RB, Blasi JR. 2010. Shared Capitalism at Work: Employee Ownership, Profit and Gain Sharing, and Broad-Based Stock Options. The University of Chicago Press: Chicago.

Lejarriaga G. 2002. The Financial Participation of the Work Force and the Creation of Value: An Operative Behavioural Proposal with Relation to Business Objectives, CIRIEC-España. Journal of Public, Social and Cooperative Economy 40: 73-98.

Lowitzsch J, Dunsch S, Hashi I. 2017. Spanish Sociedades Laborales-Activating the Unemployed. A Potential New EU Active Labour Market Policy Instrument Palgrave Macmillan, https://doi. org/10.1007/978-3-319-54870-8

Lowitzsch J, Hashi I, Woodward R. 2009. The PEPPER IV Report: Benchmarking of Employee Participation in Profits and Enterprise Results in the Member and Candidate Countries of the European Union. Inter-University Centre Berlin/Split, Institute for European Studies, Free University of Berlin.

Maghraoui R, Zidai J. 2016. Effects of Employee Ownership on the Performance of French Companies SBF120: Empirical Validation. Journal of Accounting, Finance and Auditing Studies 2(4): 195-217.

Melgarejo Z, Arcelus FJ, Simon K. 2014. Managerial Performance Differences between LaborOwned and Participatory Capitalist Firms. Journal of Small Business Management 52(4): 808-828. https://doi.org/10.1111/jsbm.12056

Morris D, Bakan I, Wood G. 2006. Employee Financial Participation: Evidence from a Major UK Retailer. Employee Relations 28(4): 326-341.

Muñoz-Medrano C, Briones-Peñalver J. 2011. Good Governance in the Entities of the Social Economy. CIRIEC-España. Journal of Public, Social and Cooperative Economy 73: 171-191.

Narvaiza L, Aragon-Amonarriz C, Iturrioz-Landart C. 2016. Cooperative Dynamics During the Financial Crisis Evidence from Basque and Breton Case Studies. Nonprofit and Voluntary Sector 46: 505-524. https://doi.org/10.1177/0899764016661775

O’Boyle E, Patel P, González E. 2016. Employee Ownership and Firm Performance: A MetaAnalysis. Human Resource Management Journal 26(4): 425-448.

Poulain-Rehm T, Lepers X. 2013. Does Employee Ownership Benefit Value Creation? The Case of France (2001-2005). Journal of Business Ethics 112: 325-340.

Poutsma E, Nijs W, Poole M. 2003. The Global Phenomenon of Employee Financial Participation. International Journal of Human Resource Management 14(6): 855-862.

Renneboog L, Ter Horst J, Zhang C. 2008. The Price of Ethics and Stakeholder Governance: The Performance of Socially Responsible Mutual Funds. Journal of Corporate Finance 14(3): 302-322.

Retolaza JL, San JL. 2011. Social Economy and Stakeholder Theory, An Integrative Framework for Socialization the Capitalism. CIRIEC-España. Journal of Public, Social and Cooperative Economy 73: 193-211.

Richter A, Schrader S. 2017. Levels of Employee Share Ownership and the Performance of Listed Companies in Europe. British Journal of Industrial Relations 55(2): 396-420. https://doi.org/ 10.1111/bjir.1269.

Sengupta S, Whitfield K, McNabb R. 2007. Employee Share Ownership and Performance: Golden Path or Golden Handcuffs? International Journal of Human Resource Management 18(8): 1507-1538.

Smith S. 1991. On the Economic Rationale for Codetermination Law. Journal of Economic Behavior and Organisation 16(3): 261-281.

Tabachnick BG, Fidell LS. 1996. Using Multivariate Statistics. HarperCollins Publishers: New York.

Ward B. 1958. The Firm in Illyria: Market Syndicalism. American Economic Review 48: 566-589. 
Whitfield K, Pendleton A, Sengupta S, Huxley K. 2017. Employee Share Ownership and Organisational Performance: A Tentative Opening of the Black Box. Personnel Review 46(7): 1280-1296. https://doi.org/10.1108/PR-09-2016-0243

Wills J. 1998. A Stake in Place? The Geography of Employee Ownership and Its Implications for a Stakeholding Society. Transactions of the Institute of British Geographers 23(1): 79-94.

Zubiaurre M, Andicoechea L, Saitua A. 2016. Worker Cooperatives Versus Investor-Owned Firms. Comparative Analysis of Financial Strength and Performance in the Basque Country. CIRIECEspaña. Journal of Public, Social and Cooperative Economy 86: 155-194. 